\title{
MODELAGEM MATEMÁTICA AMBIENTAL AVALIAÇÃO DO CONFORTO TÉRMICO PARA VACAS LEITEIRAS: UM ESTUDO DE MODELAGEM GEOESTATISTICA AMBIENTAL
}

Thiago Fernandes (AUTOR PRINCIPAL) - thiago.unemat@ gmail.com Universidade do Estado de Mato Grosso - UNEMAT

Ediane Farias da Silva (COAUTOR) - ediaanefarias@ gmail.com Universidade do Estado de Mato Grosso - UNEMAT

Rodrigo Lemos Gil (COAUTOR) - rodrigogil@ florestal.eng.br Instituto Federal de Educação, Ciência e Tecnologia de Mato Grosso

Douglas Dias de Morais (COAUTOR) - douglasdias_1991@ @otmail.com Universidade de Cuiabá - UNIC.

Carlo Ralph de Musis (COAUTOR) - carlo.demusis@ gmail.com Universidade de Cuiabá - UNIC.

Ramão Humberto Martins Manvailer (COAUTOR) - ramaominter@ gmail.com Universidade do Estado de Mato Grosso - UNEMAT.

Resumo: O objetivo do presente trabalho foi avaliar o ambiente térmico de vacas leiteiras, em apenas uma estação do ano (chuvosa), no município de Nova Olímpia, Mato Grosso. Os dados foram conquistados por meio do uso de equipamento construído, conhecido como transecto móvel, com dois sensores embutidos (RHT03), sendo um de temperatura do ar $\left({ }^{\circ} \mathrm{C}\right.$ ) e outro de umidade relativa do ar (UR\%). O processo metodológico compreendeu duas etapas, sendo uma a coleta de dados meteorológicos a campo, e a segunda, como sendo a modelagem matemática desses, por meio da geoestatistica. Assim, concluímos que o ambiente pelo qual esses animais estão sendo expostos não apresentam condições naturais que os ajudem a se sentirem menos desconfortáveis. A exemplo disso, mencionamos a pouco existência de vegetação e a sua má distribuição dentro da área. Portanto, produtividade de leite está diretamente ligada ao tempo em que o animal está submetido à zona termo neutra, ou seja, quanto maior o tempo em que o animal permanece em conforto maior será sua produtividade.

Palavras-chave: Biociência, Conforto ambiental, Geoestatistica, Modelagem, Qualidade do Leite.

\section{INTRODUÇÃO}

O Brasil acaba oportunizando uma autonomia maior devido sua expansão territorial, na qual Mezzadri (2007) discute que isso acontece pelo fato do país possuir grandes 

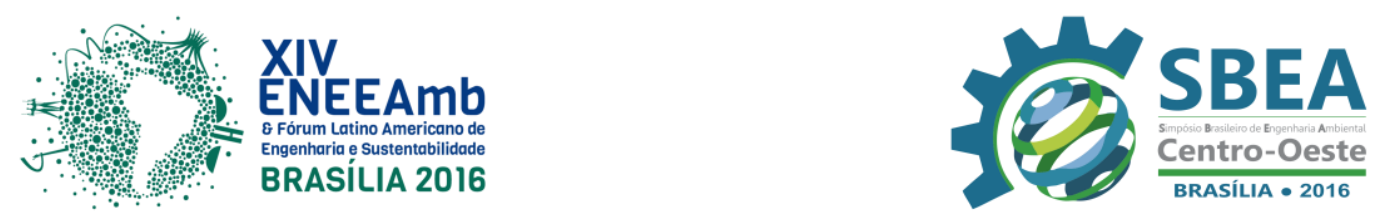

abundâncias de espécies forrageiras e raças bovinas de grande produtividade, pelo qual acabam se adaptando perfeitamente as condições de ambiência do território.

Para Gomes (2012) a produção no estado de Mato Grosso, que envolve diretamente o setor agropecuário, caracteriza-se em dois lados, sendo um a produção de leite que influencia uma pequena parte em termos de mercado nacional, comparado ao estado de Minas Gerais, que detém grande percentual da manufatura desta matéria prima, e o outro lado, predomina a produção de soja, algodão e pecuária de corte, que para esses casos, já ocupam um bom mercado nacional.

Ainda Gomes (2012) a área predominante no estado de Mato Grosso com relação ao de produção de pastagem é o extensivo, ou seja, a base da alimentação ainda é o pasto. As maiores partes dos produtores rurais utilizam o capim predominador das pastagens para o livre acesso dos animais em comparado aos outros grandes centros de produção leiteira que, $55 \%$ utilizam o confinamento para o aumento da produtividade para rendimentos econômicos, por meio do controle das condições ambientais na área do alojamento (PERISSINOTTO et al., 2009).

Assim, temos que o objetivo deste trabalho foi avaliar o ambiente térmico de vacas leiteiras para apenas uma estação do ano (chuvosa), no município de Nova Olímpia, Mato Grosso.

\section{METODOLOGIA}

A pesquisa subjetiva encontrar a temperatura e umidade relativa do ar adequada para as vacas leiteiras por meio de uma experimentação in loco. O estudo foi realizado na Fazenda da Saudade, em uma área rural de pequena produção de gado, localizada a $4 \mathrm{~km}$ do município de Nova Olímpia-MT. Essa região está situada a $14^{\circ} 47^{\prime} 06.2^{\prime \prime}$ de latitude sul e $57^{\circ} 18^{\prime} 26.6^{\prime \prime}$ de longitude oeste e a $204 \mathrm{~m}$ de altitude. O clima de acordo com a classificação de KöppenGeiger é do tipo Aw (clima tropical), com temperatura média do mês mais frio do ano $>18^{\circ} \mathrm{C}$, embora apresente estações secas e com chuvas predominantes no verão (SENTELHAS, 1998).

A seguir, na figura 01, mostra-se a localização geográfica exata da área onde foram realizadas as medições de temperatura e umidade.
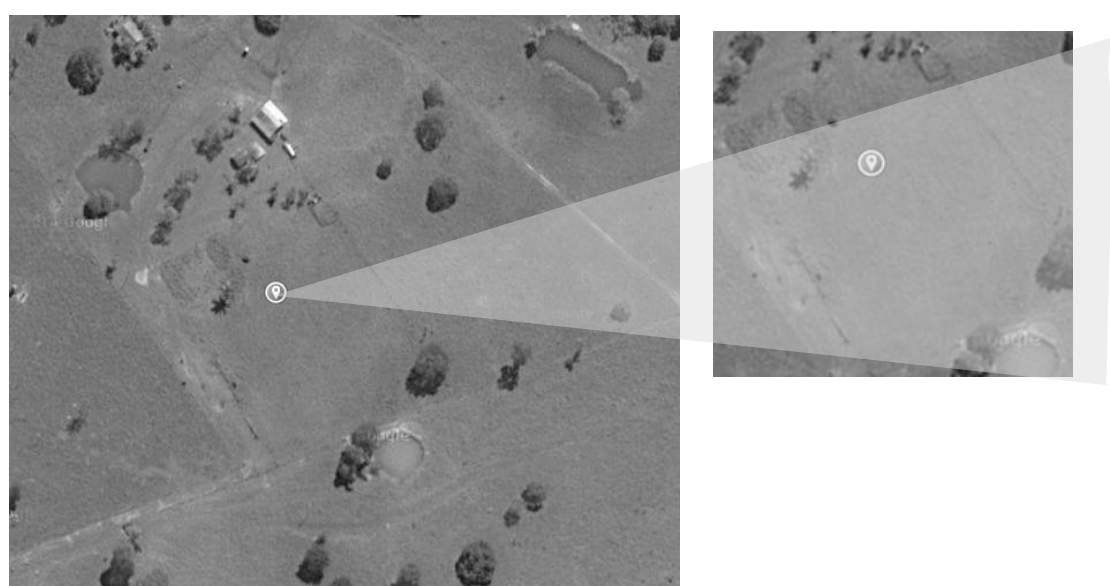

Figura 1: Localização geográfica da criação de vacas leiteiras, Fazenda da Saudade, Nova Olímpia-MT.

Fonte: Google Maps, 2016. 

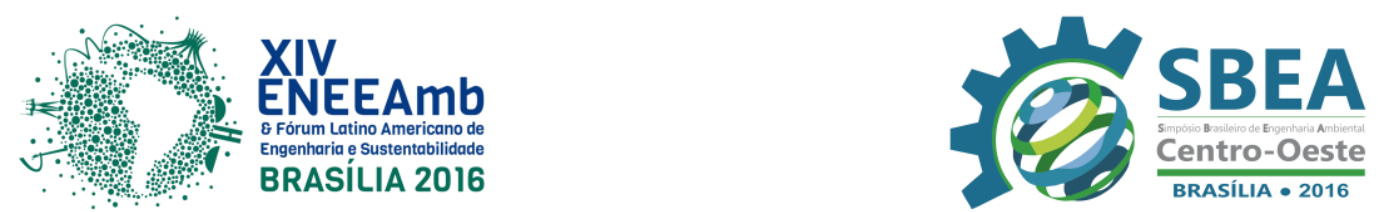

A Fazenda da Saudade localiza-se na região sudoeste do Estado de Mato Grosso e possui uma área total de aproximadamente $919,600 \mathrm{~m}^{2}$, sendo que a área de estudo possui $10.645,09 \mathrm{~m}^{2}$. A pesquisa foi dividida em duas etapas, sendo a Etapa 1 com a coleta de dados, que ocorreu no dia 31 de janeiro do ano de 2016, totalizando 1 dia de coleta (período matutino). Já a Etapa 2, se restringiu a tabulação dos dados e construção dos mapas temáticos por variáveis. Como já referendado, as coletas foram realizadas em um único período (matutino), dentre as 09:00h ás 11:00h, considerando um tempo de medição máximo de 15 minutos.

Para (BARROS, 2012) em sua tese de doutorado publicada com o título Dimensão fractal e ilhas de calor urbanas: uma abordagem sistêmica sobre as implicações entre a fragmentação das áreas verdes e o ambiente térmico do espaço urbano, a WMO recomenda que as principais observações meteorológicas de um dia típico devam acontecer às $00 \mathrm{~h}, 06 \mathrm{~h}$, 12 h e 18 h GMT (Greenwich Meridian Time), correspondentes às 20 h, 02 h, 08 h e 14 h, horário local.

\subsection{EQUIPAMENTOS E MATERIAIS UTILIZADOS}

Os equipamentos e materiais utilizados para obtenção dos dados de temperatura do ar $\left({ }^{\circ} \mathrm{C}\right)$ e umidade relativa (\%UR) na área de estudo foram:
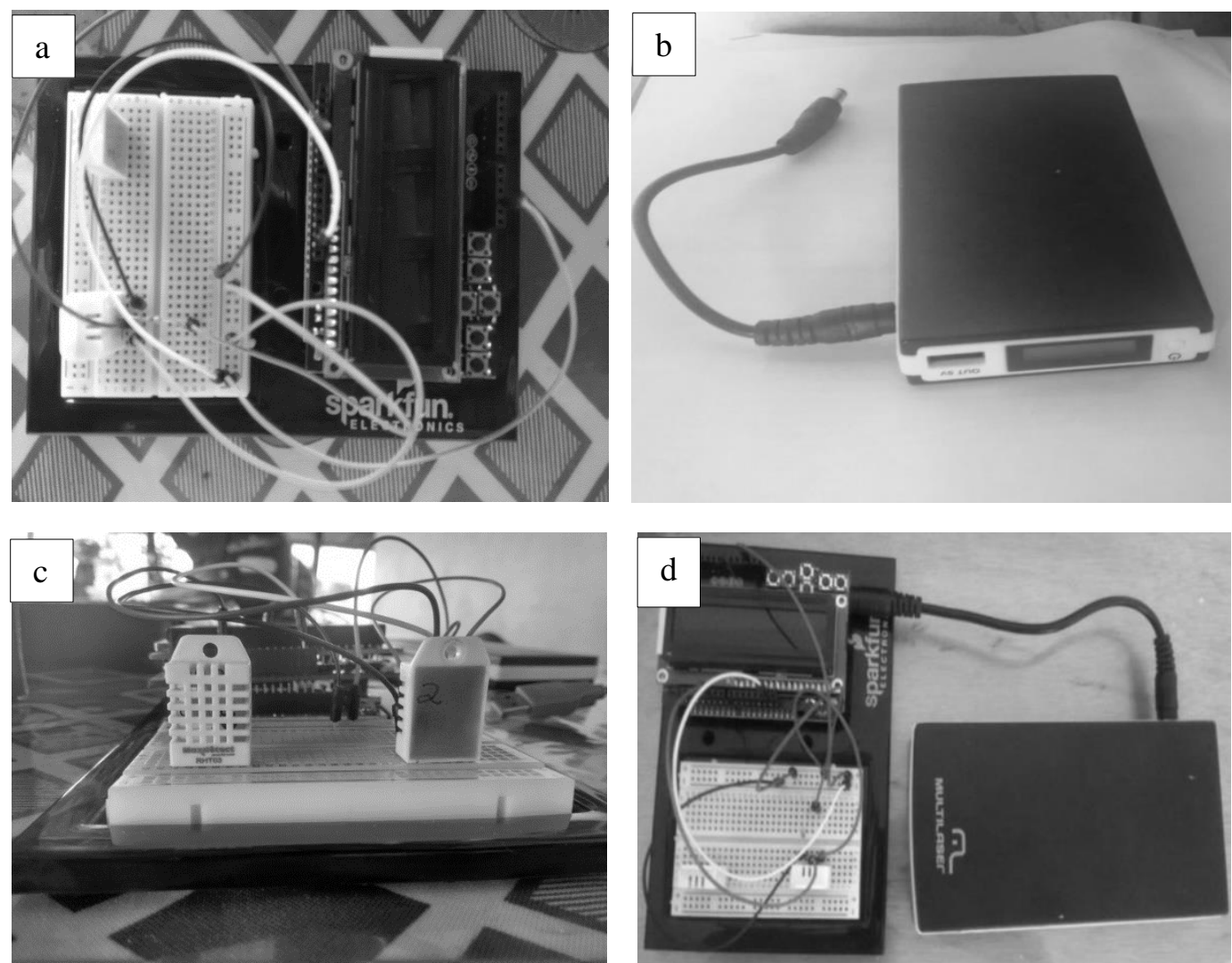

Figura 2: Materiais e equipamentos utilizados na obtenção dos dados de temperatura e umidade relativa na área de estudo. (a) 1 (um) Kit arduino da marca Spartksun Electronics para montagem do data logger de temperatura e umidade relativa; (b)1(uma) bateria de 12 Volts da marca Multilaser; (c) 1 (um) sensor RHT03 de temperatura e 1 (um) de umidade relativa do ar e (d) transecto móvel montado. 

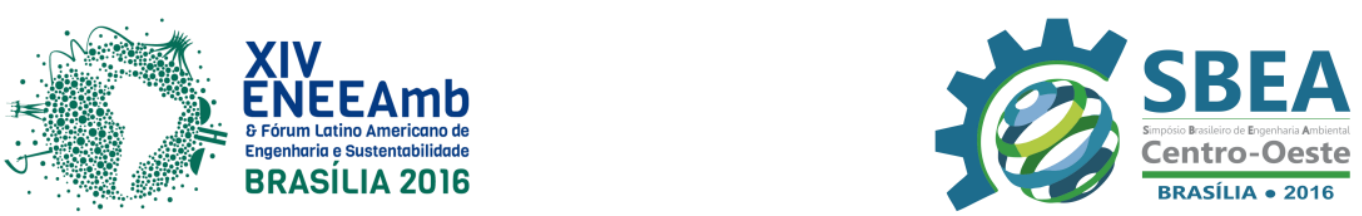

\section{RESULTADOS E DISCUSSÕES}

Para aferirmos o conforto térmico em um local que se desenvolva a criação de vacas leiteiras, é recomendado que se analise o comportamento das variáveis de temperatura do ar $\left({ }^{\circ} \mathrm{C}\right)$ e umidade relativa (\%UR) coletada durante um dia.

As tipologias dos mapas utilizados neste trabalho foram do tipo contornos, sendo que estes apresentam curvas de isovalores, que, nas concepções de Souza et al. (2014) é quando se une todos os pontos com a mesma altitude ou cota.

\subsection{MANIPULAÇÃO DOS DADOS}

Os dados foram manipulados através da utilização do aplicativo "Minhas Trilhas" da Google, que nos informou os pontos de marcação georreferenciados. Esses dados obtidos foram inseridos em um software chamado Trackmaker, com a objetividade de transformar esses que se encontravam no formato (GPX) em formato de Excel.

Mensuramos os dados de temperatura do ar $\left({ }^{\circ} \mathrm{C}\right)$ e umidade relativa do ar (\%UR) através do transecto móvel, construído a partir do data logger. Ambos os dados foram unificados utilizando-se o software "GS+" para gerar a krigagem ordinária. E por fim, houve a utilização do software de modelagem geoestatística chamado "SURFER versão 13", que através deste, foi gerado os mapas de distribuição espacial e seu comportamento das variáveis estudadas.

\subsection{PERÍODO EM RELAÇÃO À ESTAÇÃO CHUVOSA}

A coleta de dados foi realizada no período que transude a estação chuvosa, ou seja, meados de dezembro até final de março. A coleta foi proferida durante um dia típico, sem a presença de nuvens. Esse critério é preciso para que se possam obter melhores resultados em relação ao período da matutino, analisando as temperaturas e umidades relativas do ar.

\subsubsection{TEMPERATURA MATUTINA}

Os dados obtidos em relação à temperatura do ar $\left({ }^{\circ} \mathrm{C}\right)$ no período matutino apresentaram uma variação, entre $25,2{ }^{\circ} \mathrm{C}$ a $26,3{ }^{\circ} \mathrm{C}$. Torna-se importante lembrar que houve uma ocorrência de uma chuva de aproximadamente 50 minutos um dia anterior ao dia da realização da coleta de dados.

Entretendo, considera-se o dia da coleta, como um dia normal e típico, devido a não presença de nuvens. Os primeiros dados podem ser verificados na figura 3, a seguir, na qual possibilita fazermos algumas inferências, tais como: 


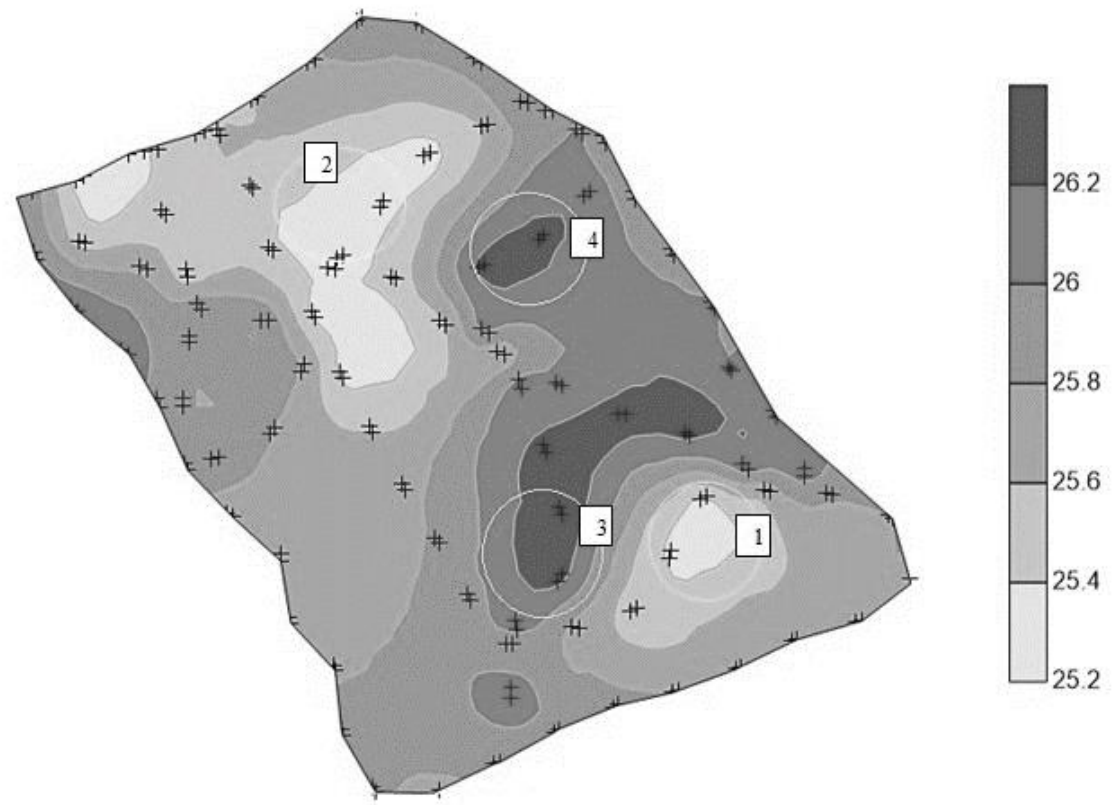

Figura 3: Temperatura do ar $\left({ }^{\circ} \mathrm{C}\right)$ para o período matutino.

Fonte: Elaborado pelos autores, 2016.

Nota-se que ao visualizar o mapa de temperatura do ar $\left({ }^{\circ} \mathrm{C}\right)$ para o período matutino, percebemos locais com manchas claras e escuras, ou seja, isso demostra o nível de temperatura em cada local em que se transitou com o aparelho transecto móvel. De certo modo, os locais com manchas mais claras são as quais as temperaturas estavam mais baixas naquele exato momento e, conseguinte, os locais com predominância de manchas mais escuras correspondem aonde à temperatura demonstrou ser mais elevada.

Os locais destacados através da numeração 01, 02, 03 e 04, são locais específicos que demostram predominância de temperaturas altas e baixas relativas. Assim, o local $01 \mathrm{em}$ destaque, contornados por seus isovalores, demonstra que a temperatura naquele momento foi de $25,5^{\circ} \mathrm{C}$, porém, dentro deste contorno de isovalores se encontram também a temperatura mais baixa, que foi de $25,2{ }^{\circ} \mathrm{C}$. Essa mancha de característica bem mais clara observado no local 01 é possível seu aparecimento devido encontrar neste ambiente uma vegetação de grandes arbustos, o que possibilita um sombreamento, interferindo naturalmente na diminuição da temperatura.

Para (BARBOSA \& DAMASCENO, 2002) a melhor sombra é provida de árvores, que podem se encontrar tanto insoladas ou em grupos, e devem estar presentes nos pastos, para a fim de proteger as vacas de radiação solar e ajudar a diminuir a temperatura do ar, principalmente no período do verão. Observou que neste local encontra-se apenas uma arvora da espécie figueira (Ficus), inferindo que o posicionamento desta proporciona uma grande sombra, perfazendo com que haja uma concentração de vacas leiteiras naquele local, conforme ilustra a figura 4 , respectivamente. 


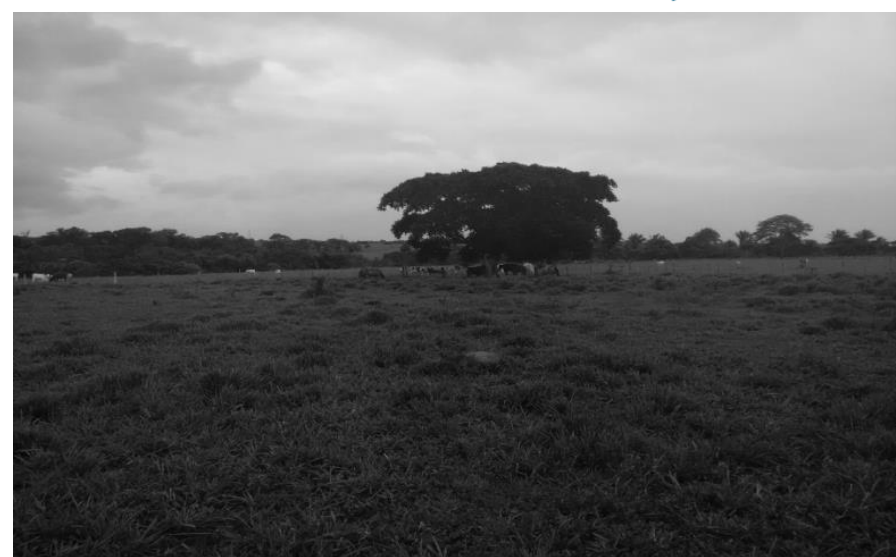

Figura 4: Árvore da espécie Figueira (Ficus) localizada em uns dos pontos onde a temperatura do ar apresentou ser menor.

Fonte: Elaborado pelos autores, 2016.

Discorremos que a temperatura do ar $\left({ }^{\circ} \mathrm{C}\right)$ que aferiu ser baixa neste local 02 , é proveniente não só da espécie vegetal Coqueiro Babaçu (Orrbignya speciosa), mais se obtém a influência de outra represa que se localiza próxima área, ou seja, desta forma, nos dois lados da área possuem a existências de represas, que possivelmente auxiliam na amenização das temperaturas próximas ao cercamento, conforme direção dos ventos. Em relação aos locais circulados e renomeados no mapa como 03 e 04, nestes podemos perceber que estão selecionadas as altas temperaturas do ar $\left({ }^{\circ} \mathrm{C}\right)$. Essas temperaturas se encontram a um valor de $26,1^{\circ} \mathrm{C}$, observados através da curva de isovalores. Entretanto, percebe-se também que nestes mesmos locais, se localizam a temperatura máxima coletada para o período matutino, que foi de $26,3{ }^{\circ} \mathrm{C}$.

\subsubsection{UMIDADE MATUTINA}

Os dados obtidos em relação à umidade relativa do ar (\%UR) apresentaram uma variação entre $81,2 \%$ a 84,8\%. Na figura 5, a seguir, demonstra sua melhor visualização.

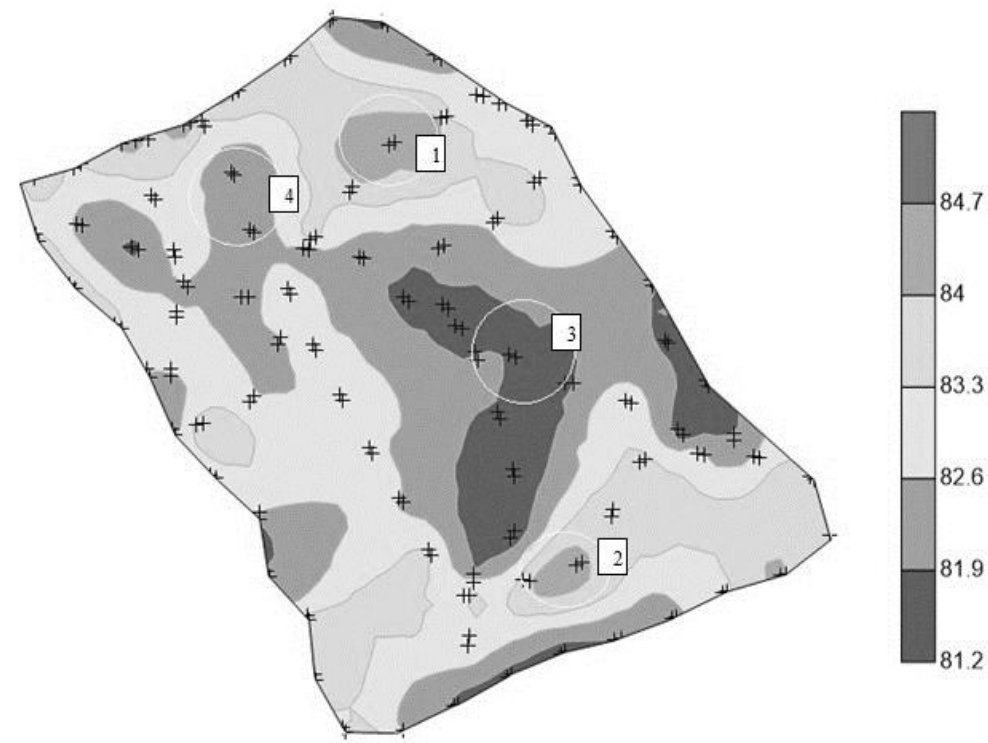

Figura 5: Umidade relativa (UR\%) para o período matutino.

Fonte: Elaborado pelos autores, 2016. 

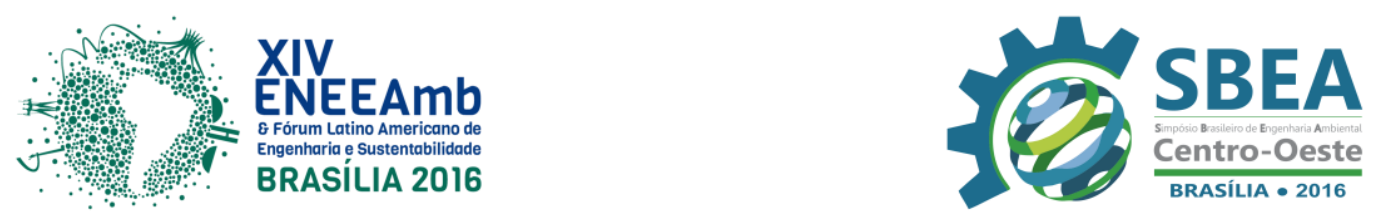

Os locais com tonalidades escuras e os outros locais com tonalidades claras, observadas na figura 5, referem-se à concentração de dados de umidade relativa do ar (\%UR). De acordo com Falcão et al. (2010) a umidade relativa do ar (\%UR) é influenciada pela temperatura do ar $\left({ }^{\circ} \mathrm{C}\right)$, em que quando a temperatura está baixa a umidade relativa do ar irá se encontrar alta, portanto, pode-se considerar também seu inverso. Ainda na figura 5, mostra alguns locais destacados para melhor análise desta conversação levantada, sendo destacados como locais $01,02,03$, e 04 , respectivamente.

O local 01, conforme enumerado, demostra que a sua umidade no momento da coleta foi de $84 \%$, ou seja, pelos padrões de analises, uma umidade relativa considerável. Esta alta da umidade relativa do ar (\%UR) foi influenciada por uma vegetação alta conhecida como Capim-Mombaça (Megathyrsus maximus), e que, por devido estarmos no período chuvoso, provocou o crescimento elevado desta vegetação, estando a aproximadamente $60 \mathrm{~cm}$ de altura da superfície.

Já para o local 02, como destacado no mapa, este evidenciou uma umidade elevada de $83,3 \%$ e outra de $84 \%$. Isso pode ser explicado pelo fato de nesta área compor vegetação de grandes arbustos, que possibilitou certamente em ter uma umidade relativa do ar sem muitas alterações. Na concepção de Dhal (2010), este alega que quando a umidade relativa do ar (UR\%) é muito elevada, pode comprometer a capacidade da vaca de dissipar calor para o ambiente, ocasionando a diminuição da produção.

Nos locais destacados no mapa como 03 e 04, estes possuem uma área aberta, não havendo a presença e/ou existência de vegetação. Esta área aberta foi destaque no mapa de temperatura matutina e volta a ser discutida neste mapa de umidade relativa, ou seja, na falta de presença de vegetação, os dados se comportaram parecidos, devido não constituir nenhuma interferência que possa alterar a ambiência e suas relações.

\section{CONSIDERAÇÕES FINAIS}

Após discussão dos dados, é passivo de afirmarmos que os animais se comportam dentro de certos padrões e uma dada alteração ambiental comumente estimula mais de uma resposta comportamental, dentre as respostas o animal aprende a usar aquela que for mais eficiente. Como os bovinos são animais homeotérmicos, ou seja, a maior parte da energia térmica presente em seu organismo é gerada a partir dos processos metabólicos e o restante procedente do meio ambiente, em situações de desconforto térmico os animais ativam o sistema termorregulador.

Assim, concluímos que o ambiente pelo qual esses animais estão sendo expostos não apresentam condições naturais que os ajudem a se sentirem menos desconfortáveis. A exemplo disso, mencionamos a pouco existência de vegetação e a sua má distribuição dentro da área. Foram observados poucos locais onde a temperatura e as umidades relativas do ar condicionaram reguladoras, ou seja, ainda que haja alguns pontos que tenham arvores grandes, as grandes aglomerações desses animais em um só espaço, faz com que este ambiente fique desproporcional.

As presenças de represas próximas não chegaram a afetar diretamente a temperatura e muito menos a umidade relativa. Tanto o posicionamento do sol, poucos ventos, falta de arvores, dentro outros, contribuem para que esteja área não se caracterize como ideal. Ainda que tenha fartura em alimentação (pasto), a radiação solar direta faz com que todo esse alimento seja convertido em energia, ocorrendo o que chamamos de estresse térmico. 

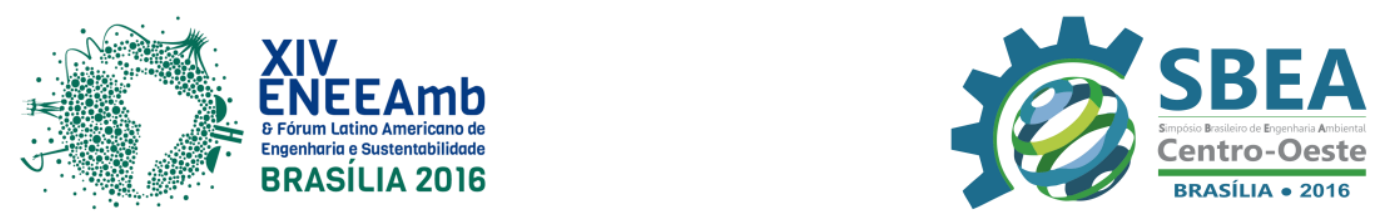

O efeito do estresse térmico no desempenho e no comportamento animal, possivelmente será um problema crescente devido às altas taxas populacionais. Somente o trabalho em conjunto dos técnicos produtores e pesquisadores poderá diminuir os efeitos do estresse térmico, buscando alternativas viáveis e adaptadas a cada situação.

\section{REFERÊNCIAS}

BARBOSA, O. R.; DAMASCENO, J. C. Bioclimatologia e bem-estar animal aplicado à bovinocultura de leite. Universidade Estadual de Maringá, Maringá, PR, Jun 2002.

BARROS, M. P de. Dimensão fractal e ilhas de calor urbanas: uma abordagem sistêmica sobre as implicações entre a fragmentação das áreas verdes e o ambiente térmico do espaço urbano. Tese (doutorado) -- Universidade Federal de Mato Grosso, Instituto de Física, Programa de Pós-Graduação em Física Ambiental, Cuiabá, 2012.

DAHL, G. Efeito do estresse térmico durante o período seco no desempenho pós-parto. In: Anais do $14^{\circ}$ Curso Novos Enfoques na Produção e Reprodução de Bovinos; 2010, Uberlândia. Uberlândia: Conapec Jr; 2010. p.357-62.

GOMES, S. T. Diagnóstico da cadeia produtiva do leite no Estado de Mato Grosso: relatório de pesquisa, 2012. Disponível em:

<http://www.imea.com.br/upload/pdf/arquivos/Microsoft_Word_Diagnostico_da_Cadeia_do_ Leite_MT_Final_.pdf >. Acesso em: 14 de jan de 2016.

MEZZADRI, F. P. Cenário Atual da Pecuária de Corte - Aspectos do Brasil com Foco no Estado do Paraná - Ano 2007. - Curitiba: SEAB/DERAL/DCA, 2007.

PERISSINOTTO, M.; MOURA, D. J.; CRUZ V. F.; SOUZA, S. R. L.; LIMA, K. A. O.; MENDES, A. S. Conforto térmico de bovinos leiteiros confinados em clima subtropical e mediterrâneo pela análise de parâmetros fisiológicos utilizando a teoria dos conjuntos fuzzy. Ciência Rural, v.39, p.1492-1498, 2009.

SENTELHAS, P. C. Estimativa diária da evapotranspiração de referência com dados da estação meteorológica convencional e automática. 1998. 97p. Tese (Doutorado em Irrigação e Drenagem) - Escola Superior de Agricultura "Luiz de Queiroz", Universidade de São Paulo, Piracicaba, 1998.

SOUZA, Z. M de. et al. Número de amostras na análise geoestatística e na krigagem de mapas de atributos do solo. 2014. Disponível em:

<http://www.scielo.br/scielo.php?script=sci_arttext\&pid=S0103-84782014000200011>.

Acesso em: 14 de abr. 2016. 